\title{
Developing and evaluating a team development intervention to support interdisciplinary teams
}

www.cambridge.org/cts

\section{Implementation, Policy and Community Engagement Research Article}

Cite this article: Morgan SE, Mosser A, Ahn S, Harrison TR, Wang J, Huang Q, Reynolds A Mao B, and Bixby JL. Developing and evaluating a team development intervention to support interdisciplinary teams. Journal of Clinical and Translational Science 5: e166, 1-13. doi: $10.1017 /$ cts.2021.831

Received: 29 January 2021

Revised: 22 July 2021

Accepted: 29 July 2021

\section{Keywords:}

Team science; team development; interdisciplinary teams; workshop evaluation

\section{Address for correspondence:}

S. E. Morgan, PhD, Communication Studies, Communication International Building Room 5051D, University of Miami, Coral Gables, FL 33146. Email: semorgan@miami.edu
Susan E. Morgan ${ }^{1}$, Alexandra Mosser ${ }^{2}$, Soyeon Ahn ${ }^{3}$, Tyler R. Harrison ${ }^{1}$, Jue Wang ${ }^{3}$, Qian Huang ${ }^{4}\left(\mathbb{D}\right.$, Ashley Reynolds ${ }^{4}$, Bingjing $\mathrm{Mao}^{4}$ and John L. Bixby ${ }^{5}$

${ }^{1}$ Communication Studies, University of Miami, Coral Gables, FL, USA; ${ }^{2}$ Office of the Vice Provost for Research, University of Miami, Coral Gables, FL, USA; ${ }^{3}$ Educational and Psychological Studies, University of Miami, Coral Gables, FL, USA; ${ }^{4}$ School of Communication, University of Miami, Coral Gables, FL, USA and ${ }^{5}$ Molecular and Cellular Pharmacology; Neurological Surgery, University of Miami, Coral Gables, FL, USA

\begin{abstract}
Introduction: Incentivizing the development of interdisciplinary scientific teams to address significant societal challenges usually takes the form of pilot funding. However, while pilot funding is likely necessary, it is not sufficient for successful collaborations. Interdisciplinary collaborations are enhanced when team members acquire competencies that support team success. Methods: We evaluated the impact of a multifaceted team development intervention that included an eight-session workshop spanning two half-days. The workshop employed multiple methods for team development, including lectures on empirically supported best practices, skills-based modules, role plays, hands-on planning sessions, and social interaction within and across teams. We evaluated the impact of the intervention by (1) asking participants to assess each of the workshop sessions and (2) by completing a pre/postquestionnaire that included variables such as readiness to collaborate, goal clarity, process clarity, role ambiguity, and behavioral trust. Results: The content of the team development intervention was very well received, particularly the workshop session focused on psychological safety. Comparison of survey scores before and after the team development intervention indicated that scores on readiness to collaborate and behavioral trust were significantly higher among participants who attended the workshop. Goal clarity, process clarity, and role ambiguity did not differ among those who attended versus those who did not. Conclusions: Multicomponent team development interventions that focus on key competencies required for interdisciplinary teams can support attitudes and cognitions that the literature on the science of team science indicate are predictive of success. We offer recommendations for the design of future interventions.
\end{abstract}

(C) The Author(s), 2021. Published by Cambridge University Press on behalf of The Association for Clinical and Translational Science. This is an Open Access article, distributed under the terms of the Creative Commons AttributionNonCommercial-NoDerivatives licence (http:// creativecommons.org/licenses/by-nc-nd/4.0/), which permits non-commercial re-use, distribution, and reproduction in any medium, provided the original work is unaltered and is properly cited. The written permission of Cambridge University Press must be obtained for commercial re-use or in order to create a derivative work.

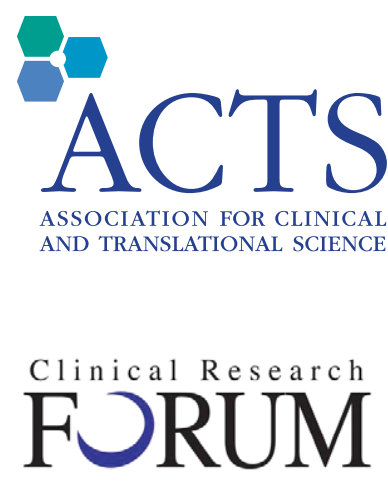

Analysis. Advocacy. Action.

\section{Introduction}

While there is a clear consensus on the importance of encouraging interdisciplinary team science as a way to generate innovative solutions to pressing scientific and societal challenges, realworld programs to advance this goal have generally been confined to offering incentives for team formation. The assumption appears to be some variation on, "if you pay them, they will come." Researchers may be more than willing to accept funding to embark on interdisciplinary endeavors, but simply bringing intelligent, hard working, and well-intentioned scholars and scientists together is no guarantee of success [1]. Thus, providing other kinds of support for interdisciplinary teams may well be a wise (and modest) investment relative to direct support for research, yielding a higher rate of return. Many universities and institutes provide infrastructure to help incubate interdisciplinary teams, including physical spaces for collaborative teams $[2,3]$ and administrative support for project management, including scheduling and coordination of team activities and help with the development of large external grant proposals (e.g. UC San Francisco, University of Michigan, University of Florida). Support for the unique needs of interdisciplinary teams can include identification of appropriate team members across disciplines, provision of space in discipline-neutral locations, conflict mediation services, and specialized development interventions designed to help team members develop collaboration skills and knowledge of best communication practices [2-4].

In this study, we focus on the importance of team development and offer an empirical analysis of the effects of a multimodule team science workshop offered to intact, novel teams (i.e., teams of individuals who have not worked together before) tackling grand challenges to society. Any institution investing substantial resources to cultivate interdisciplinary research will want to maximize the return on investment; however, few organizations offer team development opportunities as a way to maximize the chances of team success. This study (1) provides important information on how to create a team development program and (2) provides preliminary evidence of the effectiveness of such a program. 


\section{The Importance of Team Development Interventions}

Recognition of the importance of team development for the success of interdisciplinary teams is relatively recent, with rigorous empirical evaluations being conducted only within the last decade $[1,3]$. The fact that there are still few studies on the effects of interventions is likely due to the lack of resources dedicated to programs within universities, research centers, and institutes. This may be driven by a widespread assumption that if scholars are successful in their own disciplines, they will have little difficulty acquiring the skills required to collaborate with other successful scholars, even if they work in other fields. Unfortunately, technical expertise in a specific field is a poor predictor of a researcher's ability to function as a member of a team [5]. As the recognition of this fact has grown, team development has been identified as a priority area for empirical work in the science of team science (SciTS) [6]. This is particularly true for cognitively diverse teams, where team members are drawn from widely divergent fields [7]. There are many funding initiatives that prioritize the union of STEM and non-STEM fields, for example, but while the difficulties of collaboration are well-documented, practical solutions to this problem have been slow to emerge $[8,9]$.

Challenges associated with fostering collaboration are often linked to the ways in which researchers are trained and socialized. Discipline-specific training rarely even acknowledges the importance of learning how to collaborate across fields [10]; opportunities to learn collaborative skills and cross-disciplinary perspectives on a problem are rare [11]. However, these skills can be acquired at any point in a researcher's career, which means that improving competencies related to team science is not only a means of enhancing the likelihood of success for the team, but constitutes a route for meaningful faculty development. An empirically based development program, if well-executed, is highly likely to have important long-term outcomes that are favorable to both team scientists and the institutions that employ them. There are indications that faculty who successfully collaborate on an interdisciplinary team publish more and generate higher impact publications [12] and are more likely to engage in future collaborations [13]. Effective team development programs help to overcome challenges associated with team science, including challenges created by large team size, geographic dispersion, cognitive diversity, task interdependence, and the need to integrate knowledge across diverse disciplines [10]. Thus, universities that seek to increase their impact and to elevate their profiles may do well to create or support programs that provide these critical skills.

There is growing evidence that interdisciplinary team development programs help teams and individual researchers generate higher-impact outcomes [14]. Generally, team building involves exercises that help teams set goals, develop interpersonal relationships among members, engage in productive problem-solving, and clarify individual roles on the team [15]. These processes overlap with many of the competencies that are the focus of interventions designed to improve collaboration. Additionally, team development activities constitute a set of shared experiences, particularly when teams participate in development modules as a group. In turn, these shared experiences support the development of relationships within teams, which is critical to the processes that support team success [16].

\section{Team Science Competencies}

Empirical work on team development interventions focuses on a wide range of competencies. The competencies that have been identified in these studies are generally derived from interview, focus group, and survey studies of leaders of scientific teams (especially principal investigators/PIs) [9,17-22] and leaders of Clinical and Translational Science Institutes (CTSIs) [23-25]. While researchers focused on the science of team science are still working toward general agreement on a single set of team science competencies that should be part of an intervention (for example, see the work of Begg [23]), there is some notable overlap in the knowledge, skills, and abilities that have been the subject of previous studies, which indicates that there is a set of priorities that can serve as a starting point. These include knowledge about best practices in interdisciplinary research [26-28], communication skills [3,6,10,20,22,23, 26,29-33], interpersonal relationship development and maintenance $[3,6,20,29,30]$, meeting management and task coordination $[20,30,32]$, goal setting $[4,20,28,32]$, conflict management $[6,32]$, and leadership skills $[6,10,20,23,28,30,33]$. Modifiable individual traits that support team science include positive attitudes toward collaboration [26,28] and cognitive openness, which includes a willingness to learn about the approaches of other disciplines [23,34]. In addition to several of the competencies listed above, Verdarme and colleagues [33] recommend that mentors or program sponsors assess specific skills and knowledge of early career scientists in order to evaluate their preparedness for interdisciplinary collaborations, including deep knowledge of one's own field, critical thinking skills, computational skills, and the ability to conduct sound research in an ethical, responsible, and reproducible manner.

In a comprehensive review of programs designed to support team scientists and a report of an impressive initiative developed by the University of Texas Medical Branch's CTSI, Wooten and colleagues [28] recommend that interventions for interdisciplinary teams focus on the development of team science knowledge, collaboration skills, and positive attitudes toward collaboration. Additionally, team building is supported through activities that focus on goal setting, the creation of interpersonal relationships, and the clarification of individual members' roles. Further, they posit that programs help teams to develop a shared mental model by helping them engage in productive knowledge management and cognitive integration. The careful structure and design of programs supporting interdisciplinary team science also help teams achieve their goals by fostering broad collaborative networks spanning diverse disciplines. While Wooten et al. [28] also identify leadership skills as a potential area for professional development, they found it the most resistant to change, indicating that improving leadership abilities may be more about the timing of faculty development programs relative to the stage of a person's career and individual personalities than skills training.

A central question, of course, is whether a team science development program focused on any set of competencies related to interdisciplinary collaboration will be well-received by participants, and even more importantly, can create meaningful change [23]. Fortunately, the small body of existing empirical evidence suggests that interdisciplinary team development improves attitudes toward interdisciplinary collaborations [10,35], enhances team trust [10], increases knowledge relevant to the team's work [10,35], improves role clarity [10], enhances interpersonal communication skills $[10,36]$, and ultimately, increases team productivity, as measured by publications and citations [36,37]. Meta-analyses indicate that interventions focused on collaboration skills improve team performance as well as more proximal outcomes including cognitive, affective, and process-related outcomes [6,38]. This is highly encouraging for any organization seeking to invest in the success of teams beyond the provision of pilot funding. 
While the empirical literature supporting the efficacy of team development interventions is promising, the body of evidence is still small. We have designed an evaluation of a team science workshop to examine the impacts of an interdisciplinary team development workshop on individual and team outcomes and evaluated the outcomes by collecting data from two sources: a pre/post (T1/T2) intervention survey and a questionnaire about participants' reactions to individual sessions during the workshop itself. Combined, the data sets allow us to address the following research question and hypotheses:

RQ: Which workshop program modules were regarded the most favorably by participants?

H1: Individuals who attended a team workshop will score higher on readiness to collaborate than those who did not attend.

$\mathrm{H} 2$ : Individuals who attend a team development workshop will score higher on goal clarity than individuals who did not attend the workshop.

H3: Individuals who attend a team development workshop will score higher on process clarity than individuals who did not attend the workshop.

H4: Individuals who attend a team development workshop will exhibit less role ambiguity than individuals who did not attend the workshop.

H5: Individuals who attend a team development workshop will score higher on behavioral trust than individuals who did not attend the workshop.

H6: Teams with a higher percentage of members who attend a team development workshop will report higher levels of team satisfaction.

Focusing on the outcomes of a team development intervention allows for more precision in the development and refinement of programs for interdisciplinary research teams [10]. Toward this end, we will present information about a team science workshop and evaluations from participants as well as individual- and team-based outcomes that resulted from the workshop.

\section{Methods}

\section{U-LINK Program Description}

The University of Miami Laboratory for INtegrative Knowledge (U-LINK) program is an interdisciplinary pilot research funding program designed to incentivize highly innovative work to identify solutions to grand societal challenges. There are a number of features that the program shares with other pilot funding programs at other universities and institutes. However, although the U-LINK program is grounded in the most common recommendations that appear in the SciTS literature, we know of no other programs that include all of these research-related features. These features include: (1) focus on a grand challenge to society rather than a discrete scientific problem; (2) a Phase I/Phase II structure, where the first 9-month phase is devoted to the process of "teaming" and the second (1-year, renewable) phase is designed to support teams in pilot data collection and feasibility testing; (3) support from multiple campus stakeholders, including the university's CTSI (co-sponsorship of an additional Phase I team), the Graduate School (sponsorship of three full-time graduate fellows for Phase II teams); and the Libraries, which provide an embedded librarian for each team (please see Miller et al. [39] for details on this innovative part of the U-LINK program); (4) the requirement for all team members to attend an annual team science workshop; and (5) the requirement for teams to engage with community-based stakeholders who directly participate in the work of the team and provide an internal check on the likely viability of the solutions proposed by the teams. The activities of U-LINK, including review of applications and renewals, were guided by an internal advisory board of interdisciplinary faculty, as well as a representative of the university's development office and an administrative representative from the Libraries (herself a humanities scholar).
The U-LINK program was directed by the Vice Provost and Associate Provost for Research from 2017 to 2020.

\section{Team Development Intervention Description and Content}

Teams awarded U-LINK funding were required to attend a team development workshop on team science within a month of the start of the funding period. Because the workshop varied in content and format for each year it was offered, we have focused on the 2019 iteration. The workshop, which spanned two consecutive halfdays, was a combination of didactic presentations that provided an overview of empirical evidence, and opportunities to practice skills in communication and to conduct collaborative work designed to support long-term team functioning. We adopted a team development intervention approach that combines skill acquisition with team building (see Lacerenza and colleagues [40] for more information about types of team development interventions). As per recommendations from the empirical literature $[6,40]$, we varied modes of delivery, including lectures, demonstrations, and role plays, targeting a variety of competencies related to team science, including communication, the ability to establish psychological safety, and a focus on team processes. In particular, we asked each team to develop a team charter (colloquially termed a "research prenup") in which members agree to a process for team meetings, adding and removing team members, determining the order of co-authorship of publications, and other vital functions. This intensive intervention also served as an opportunity for U-LINK teams to engage both with their own team members and other teams, some of which may have a shared focus (e.g., threats from climate change, computation/big data). The workshop also featured a distinguished keynote speaker with expertise in the "science of team science" who offered advice to teams based on their own empirical work. See Table 1 for the relationship between workshop content and expected competencies.

\section{Development of Workshop Content}

The U-LINK workshop was developed in the same way that the ULINK pilot funding program itself was developed. First, a careful review of the literature on the key competencies related to interdisciplinary scientific team collaborations was performed. Second, this list of competencies was examined further to assess whether (1) the empirical literature linked team outcomes to these competencies and (2) evidence existed that these competencies were sensitive to training. For example, there is a near-consensus that communication skills are central to the success of teams and there is ample evidence that training programs can improve communication skills [29]. Conversely, however, while much has been made about the importance of competent leadership for the success of teams [30], there is little evidence that leadership skills can be acquired through brief interventions [28]. Thus, for our workshop, we focused on improving competencies which were most likely to respond to our intervention(s). These competencies appear in Table 1. The workshop agenda appears in Appendix A; an internal report on the workshop that includes additional details about its content can be found in the University of Miami's scholarly repository: https://doi.org/10.33596/ovprrs-19. Figure 1 represents the balance of workshop content. The content categories include lectures, discussions/role plays, and social interactions. Lectures presented during the workshop were designed to be understandable and useful to a broad audience (i.e. no undefined jargon, avoiding the presentation of academic theories, or detailed analyses). Lectures were alternated with group discussions and role plays 
Table 1. Team development workshop content, expected competencies, example activities, and study variables

\begin{tabular}{|c|c|c|c|}
\hline Team development workshop session & Expected competencies & Example activities & Dependent variable \\
\hline $\begin{array}{l}\text { An overview of the empirical evidence supporting } \\
\text { best practices for team science }\end{array}$ & $\begin{array}{l}\text { - Knowledge of best practices } \\
\text { - Attitudes toward collaboration }\end{array}$ & - Lecture on empirical evidence & - Readiness to collaborate \\
\hline $\begin{array}{l}\text { Self-assessment quiz and the establishment of your } \\
\text { team's rules }\end{array}$ & $\begin{array}{l}\text { - Knowledge about best practices } \\
\text { - Meeting management and task } \\
\text { coordination } \\
\text { - Conflict management }\end{array}$ & $\begin{array}{l}\text { - Quiz and debriefing } \\
\text { discussion }\end{array}$ & $\begin{array}{l}\text { - Process clarity } \\
\text { - Team satisfaction }\end{array}$ \\
\hline $\begin{array}{l}\text { Tech platforms for project management and } \\
\text { knowledge management options }\end{array}$ & $\begin{array}{l}\text { - Knowledge about best practices } \\
\text { - Meeting management and task } \\
\text { coordination }\end{array}$ & - Lecture providing overview & - Process clarity \\
\hline $\begin{array}{l}\text { Psychological safety exercise: what you should } \\
\text { know about me/my discipline }\end{array}$ & $\begin{array}{l}\text { - Communication skills } \\
\text { - Interpersonal relationship } \\
\text { development } \\
\text { - Cognitive openness }\end{array}$ & $\begin{array}{l}\text { - Group discussion and } \\
\text { debriefing }\end{array}$ & $\begin{array}{l}\text { - Behavioral trust } \\
\text { - Team satisfaction }\end{array}$ \\
\hline Keynote address by external team science expert & $\begin{array}{l}\text { - Knowledge of best practices } \\
\text { - Attitudes toward collaboration }\end{array}$ & $\begin{array}{l}\text { - Lecture on best practices } \\
\text { (specific topics varied) }\end{array}$ & - Readiness to collaborate \\
\hline $\begin{array}{l}\text { The importance of a team charter; creating your } \\
\text { team's charter }\end{array}$ & $\begin{array}{l}\text { - Communication skills } \\
\text { - Interpersonal relationship } \\
\text { development } \\
\text { - Goal setting }\end{array}$ & $\begin{array}{l}\text { - Group activity (using work- } \\
\text { sheet) and discussion }\end{array}$ & $\begin{array}{l}\text { - Process clarity } \\
\text { - Goal clarity } \\
\text { - Role ambiguity } \\
\text { - Team satisfaction }\end{array}$ \\
\hline $\begin{array}{l}\text { Communication behaviors that predict interdiscipli- } \\
\text { nary team success }\end{array}$ & $\begin{array}{l}\text { - Communication skills } \\
\text { - Conflict management } \\
\text { - Interpersonal relationship } \\
\text { development }\end{array}$ & $\begin{array}{l}\text { - Lecture on communication } \\
\text { skills } \\
\text { - Role play on active listening } \\
\text { - Role play on using I-Messages }\end{array}$ & $\begin{array}{l}\text { - Readiness to collaborate } \\
\text { - Behavioral trust } \\
\text { - Team satisfaction }\end{array}$ \\
\hline $\begin{array}{l}\text { U-LINK team's calendar of activities; discussing your } \\
\text { next steps }\end{array}$ & $\begin{array}{l}\text { - Goal setting } \\
\text { - Meeting management and task } \\
\text { coordination }\end{array}$ & $\begin{array}{l}\text { - Group activity using template } \\
\text { - Group discussion }\end{array}$ & $\begin{array}{l}\text { - Process clarity } \\
\text { - Goal clarity } \\
\text { - Role ambiguity }\end{array}$ \\
\hline
\end{tabular}

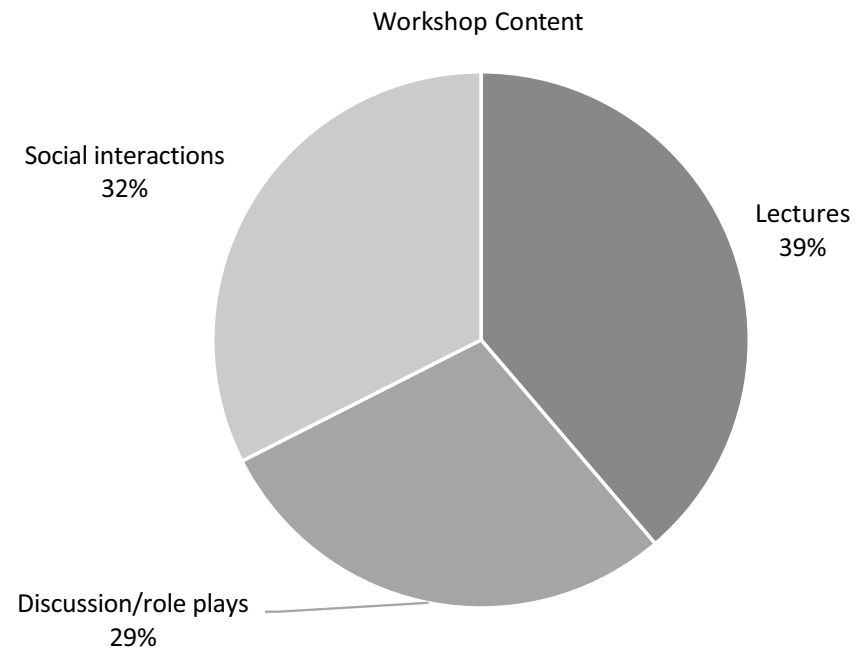

Fig. 1. Team science workshop content.

designed to give teams the opportunity to interact with each other to practice behavioral skills and to perform recommended teambased tasks, such as addressing key questions necessary to complete a team charter (i.e. authorship order considerations, agreements about meeting frequency, and format). These activities were balanced with opportunities for informal interactions among team members, including coffee breaks, meals, and a happy hour with drinks and hors d'oeuvres. It is worth noting that we also hosted a "team launch" dinner for each individual team 1-3 weeks prior to the workshop to help establish the importance of personal interactions outside of the work environment. This created another opportunity for bonding within the team and for establishing the team's "origin story" and identity. (See Bennett \& Gadlin [9] for more on the importance of team processes for team success and how social elements support this success.)

\section{Participants}

Participants in this study are members of U-LINK teams who received a Phase I and/or Phase II funding award in 2018 and 2019. Participants were faculty members and/or library staff members at the University of Miami and represent a variety of disciplines and ranks. Each team had members from at least three disciplines and ranged in size from 5 to 9 members. Disciplines represented include engineering, architecture, art, history, English, medicine, communication, public health, education, educational psychology, nursing, and psychology. While most team members were tenured (25.3\% associate professors; $20.3 \%$ full professors), a substantial minority were assistant professors $(20.3 \%)$ and several were nontenure track academic professionals $(\mathrm{n}=11$, $13.9 \%)$. While most respondents were White $(n=47,59.5 \%)$, there were respondents reporting from other racial/ethnic backgrounds $(\mathrm{n}=9,11.4 \%$ Asian; $\mathrm{n}=6,8 \%$ Hispanic; $\mathrm{n}=5,6.3 \%$ African American/Black; $n=12,15 \%$ other or did not specify). See Table 2 for characteristics of participants and nonparticipants; Table 3 provides information about the characteristics of teams.

Each survey and two follow-up requests were sent to all team members. Participants in the team development workshop were asked to complete an evaluation form at the end of each day: $69.2 \%$ responded to the survey after Day 1 and $86.5 \%$ completed the Day 2 survey. Presumably because attendance was designated as "mandatory," participation in the workshop was high 
Table 2. Characteristics of participants $(n=79)$ and nonparticipants $(n=13)$

\begin{tabular}{|c|c|c|}
\hline & Participants & Nonparticipants \\
\hline Characteristics & $n(\%)$ & $n(\%)$ \\
\hline \multicolumn{3}{|l|}{ Gender } \\
\hline Female & $33(41.8)$ & $4(30.8)$ \\
\hline Male & $39(49.4)$ & $4(30.8)$ \\
\hline Other/decline to specify & $7(8.9)$ & $5(38.5)$ \\
\hline \multicolumn{3}{|l|}{ Race } \\
\hline Asian & $9(11.4)$ & $2(15.4)$ \\
\hline Black or African American & $5(6.3)$ & $1(7.7)$ \\
\hline Non-Hispanic White & $47(59.5)$ & $9(69.2)$ \\
\hline Hispanic & $6(8.0)$ & $1(7.7)$ \\
\hline Other/Decline to specify & $12(15)$ & 0 \\
\hline \multicolumn{3}{|l|}{ Title } \\
\hline Assistant Professor & $16(20.3)$ & $2(15.4)$ \\
\hline Associate Professor & $20(25.3)$ & $3(23.1)$ \\
\hline Full Professor & $16(20.3)$ & $3(23.1)$ \\
\hline $\begin{array}{l}\text { Clinical Professor/Professor of } \\
\text { Practice/Research Professor/ } \\
\text { Director/Lecture }\end{array}$ & $3(3.8)$ & $2(15.4)$ \\
\hline Librarian & $8(10.1)$ & $3(23.1)$ \\
\hline Decline to specify & $16(9.1)$ & 0 \\
\hline \multicolumn{3}{|l|}{ Discipline } \\
\hline STEM & $20(25.3)$ & $4(30.8)$ \\
\hline Humanity and art & $21(26.6)$ & $5(38.5)$ \\
\hline Social science and law & $21(26.6)$ & $4(30.8)$ \\
\hline Decline to specify & $17(78.5)$ & 0 \\
\hline \multicolumn{3}{|l|}{ Participated in Day 1} \\
\hline Yes & $15(20.3)$ & \\
\hline No & $36(45.6)$ & \\
\hline \multicolumn{3}{|l|}{ Participated in Day 2} \\
\hline Yes & $14(17.7)$ & \\
\hline No & $38(48.1)$ & \\
\hline
\end{tabular}

(approximately 75\%) for most elements of the workshop. (Faculty with teaching conflicts moved in and out.)

\section{Data Collection Procedures}

Data for this study were drawn from two different sources. First, participants filled out a paper-based questionnaire at the end of each day, which was intended to measure the individual session's overall effectiveness, usefulness/applicability, and impacts on the team's work. Second, we collected survey data (see measures below) from grant awardees via Qualtrics. The pretest survey was emailed to all awardees 2 weeks prior to the workshop; a follow-up reminder prior to the workshop was also sent. A post-test survey was sent approximately 2 weeks after the workshop, along with a follow-up request. No incentives were provided in exchange for completing the survey. This study was determined to be exempt from IRB review because it qualifies as "process
Table 3. Characteristics of teams $(k=11)$

\begin{tabular}{|c|c|}
\hline & $n(\%)$ \\
\hline \multicolumn{2}{|c|}{ Number of members of a team } \\
\hline $1-6$ & $4(36.4)$ \\
\hline $7-10$ & $7(63.6)$ \\
\hline \multicolumn{2}{|c|}{$\%$ of women on a team } \\
\hline $0-33$ & $6(18.1)$ \\
\hline $34-66$ & $6(54.5)$ \\
\hline $67-100$ & $3(27.2)$ \\
\hline \multicolumn{2}{|c|}{$\%$ of non-White members on a team } \\
\hline $0-25$ & $8(72.7)$ \\
\hline $26-50$ & $2(18.2)$ \\
\hline More than 50 & $1(9.1)$ \\
\hline \multicolumn{2}{|c|}{$\%$ of nontenure track members on a team } \\
\hline $0-25$ & $9(81.8)$ \\
\hline $26-50$ & $2(18.2)$ \\
\hline More than 50 & $0(0)$ \\
\hline \multicolumn{2}{|c|}{$\%$ of non-STEM members on a team } \\
\hline $0-50$ & $2(18.2)$ \\
\hline $50-70$ & $4(36.3)$ \\
\hline More than 70 & $5(45.5)$ \\
\hline \multicolumn{2}{|c|}{ \% of members who attended at least one workshop session in 2019} \\
\hline $0-75$ & $9(81.8)$ \\
\hline More than 75 & $2(18.2)$ \\
\hline
\end{tabular}

improvement" rather than human subjects research. Measures described below reflect the final items used for all analyses.

\section{Measures}

\section{Evaluation of the team development workshop}

A researcher-created three-item questionnaire was used to measure participants' perception of each session's overall effectiveness, usefulness/applicability, and likely impacts on the team's work. These items were "what is your overall assessment of this session?" for overall effectiveness, "Please indicate the extent to which the session will be useful/applicable to your team's work" for usefulness/ applicability, and "Please indicate the likelihood that the session will influence my team's work" for impacts on the team's work. Items were rated on a 5-point Likert scale that ranged from "Terrible" (1) to "Excellent" (5) for overall effectiveness; "Not at all useful" (1) to "extremely useful" (5) for usefulness/applicability; and "Not at all likely" (1) to "extremely likely" (5) for impacts on the team's work.

\section{Readiness to collaborate}

Readiness to collaborate was measured using a three-item instrument that was revised from Hall et al. [41] These items were "I believe the benefits of collaboration among scientists from different disciplines usually outweigh the inconveniences and costs of such work," "There is so much work to be done within my field that it is important for me to focus my research efforts working with others in my own discipline," and "My own work can benefit from incorporating the perspectives of disciplines that are different from my own." Items were rated on a 5-point Likert scale that ranged 
from "Strongly Disagree" (1) to "Strongly Agree" (5). A composite score was created by averaging responses on five items, with higher score indicating higher level of one's readiness to collaborate. The internal consistency measured by Cronbach's alpha was below average at both time points ( $\alpha=.51$ for time $1 ; \alpha=.56$ for time 2$)$.

\section{Behavioral trust disclosure}

Behavioral trust disclosure was measured only at time 2 using a five-item instrument that was developed by Gillespie [42]. Sample items include "Share your personal feelings with your team," "Confide in your team about personal issues that are affecting your work," and "Discuss how you honestly feel about your work, even negative feelings and frustration." Items were rated on a 5 -point Likert scale that ranged from "Not at all willing" (1) to "Completely willing" (5). A composite score was created by averaging responses on five items, with higher score indicating higher level of one's willingness to share personal feelings and issues related to the work. Internal consistency was high, $\alpha=.90$.

\section{Goal clarity}

This four-item measure was revised from Sawyer's [43] measurement of goal and process clarity. Sample items include "I am clear about my responsibilities on this U-LINK team," "I am confident that I know what the goals are for my U-LINK team," and "I know how my work relates to the overall objectives of my U-LINK team." Items were rated on a 5-point Likert scale that ranged from "Strongly Disagree" (1) to "Strongly Agree" (5). A composite score was created by averaging responses on three items, with a higher score indicating a higher level of goal clarity. The internal consistency measured by Cronbach's alpha was good at each time point ( $\alpha=.90$ for time $1 ; \alpha=.93$ for time 2).

\section{Process clarity}

This three-item measure was revised from Sawyer's [43] measurement of goal and process clarity. Sample items include "I know how to go about my work on my U-LINK team," "I know how my team will move forward with its work on our U-LINK project," and "I am confident that my U-LINK team is using the right processes to move forward with its work." Items were rated on a 5-point Likert scale that ranged from "Strongly Disagree" (1) to "Strongly Agree" (5). A composite score was created by averaging responses on three items, with higher score indicating a higher level of goal clarity. The internal consistency measured by Cronbach's alpha was poor at time $1(\alpha=.56$ for time 1$)$ but was good at time $2(\alpha=.87)$.

\section{Role ambiguity}

This two-item measure was drawn from Peterson and colleagues' measurement of role ambiguity, conflict, and overload [44]. The items were "I know exactly what is expected of me on my $U$-LINK team" and "I know what my responsibilities are on my $U$-LINK team." Items were rated on a 5-point Likert scale that ranged from "Strongly Disagree" (1) to "Strongly Agree" (5). A composite score was created by averaging responses on two items, with higher score indicating less uncertainty about one's role around U-LINK team. The internal consistency measured by Cronbach's alpha was good at times $1(\alpha=.90)$ and was acceptable at time $2(\alpha=.77)$.

\section{Team satisfaction}

Team satisfaction was measured using three items that were revised from Hackman and Oldham's job satisfaction survey questionnaire [45]. Sample items include "I enjoy the kind of work we do on this U-LINK team," "Working on this U-LINK team is an exercise in frustration," (reverse-coded) and "Generally speaking, I am very satisfied with this U-LINK team." Items were rated on a 5-points Likert scale that ranged from "Strongly Disagree" (1) to "Strongly Agree" (5). A composite score was created by averaging responses on three items, with higher score indicating higher level of satisfaction with U-LINK team. The internal consistency measured by Cronbach's alpha was acceptable $(\alpha=.82)$.

\section{Analytic Strategies}

We used SPSS to first summarize participants' rating on the three proximal outcomes of each session numerically and graphically. Second, a series of repeated-measures Analysis of Variance (ANOVA) tests were performed to explore how specific sessions were perceived by participants, followed by a post-hoc analysis using Bonferroni adjustment [46]. ANOVA was conducted separately for Day 1 and Day 2 sessions. Third, a series of independent samples $t$-tests was conducted to see whether individuals who attended at least one team science workshop session scored higher on some outcomes than those who did not attend any. None of the variables measured before the team development intervention was significantly different, and thus they were not controlled in the analyses. Lastly, using the Mann-Whitney $U$ test, team-level outcomes (team satisfaction, behavioral trust, goal clarity and process clarity, and role ambiguity) were compared based on the percentage of team members who attended or did not attend at least one day of the 2-day team development workshop (i.e., Group 1 consisted of teams with $>75 \%$ attendance; Group 2 had $\leq 75 \%$ attendance). The Mann-Whitney $U$ test was used due to our small sample size ( $n=11$ teams), and its effect size was computed based on the formula provided by Kerby [47].

\section{Results}

\section{Team Characteristics}

The number of team members ranged from 5 to $9(M=7.18$, $S D=1.25)$. The percentage of male team members varied from 0 to $75 \%(M=50.69 \%, S D=26.84 \%)$. Six teams composed of more females and five teams with fewer females. Years of U-LINK funding ranged from 1 to 2 . The percentage of team members who participated in the 2-day team development workshop varied from $0 \%$ $(n=1)$ to $100 \%(n=1)$, with a total of 52 participants on Day 1 and 52 on Day 2. Some participants attended both days, while some attended only one or the other. Of those who attended, 36 on Day 1 and 45 on Day 2 filled out a paper-format survey questionnaire that measured the three proximal outcomes of each workshop session: overall effectiveness, usefulness/applicability, and likely impacts on the team's work.

\section{Teams' Evaluation of Workshop Sessions}

The first research question focused on how participants evaluated the team science workshop sessions. Figures 2-7 present the means of the evaluations for each of the workshop topics. Repeated measures ANOVA indicated that there were no group differences in the change score. Mean participants' rating on the perceptions of the team development intervention at time 2 varied by individual session: $3.94-4.72$ for overall effectiveness, $3.74-4.32$ for usefulness/applicability, and 3.91-4.18 for impacts on the team's work. Most participants perceived all of the sessions to be effective, useful/applicable, and impactful on their ability to work as a team, 


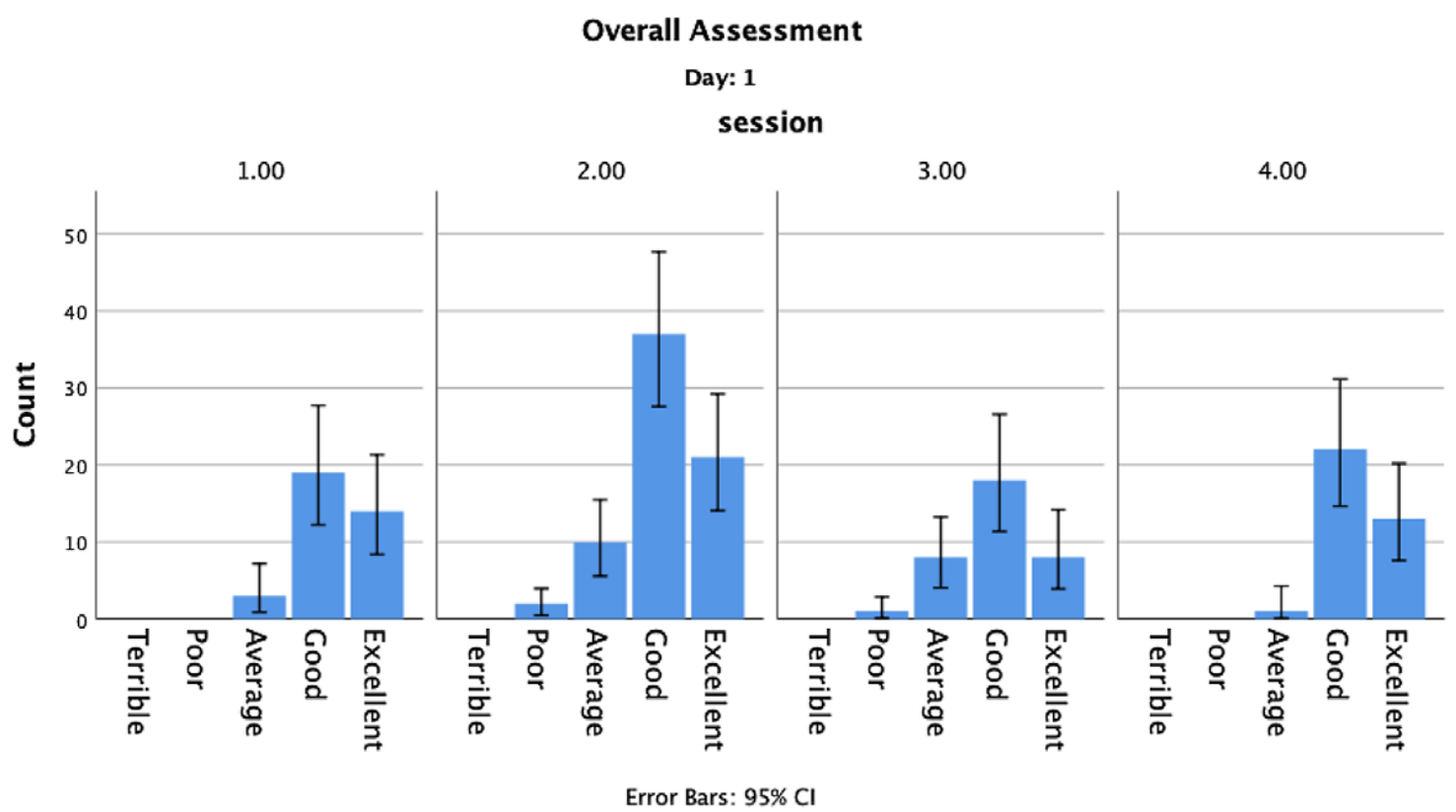

Fig. 2. Participants' ratings on Day 1 sessions: overall assessments.

Session 1: An overview of the empirical evidence supporting best practices for team science

Session 2: Self-assessment quiz and the establishment of your team's rules

Session 3: Tech platforms for project management and knowledge management options

Session 4: Psychological safety exercise: What you should know about me/my discipline

Pereceived Usefulness

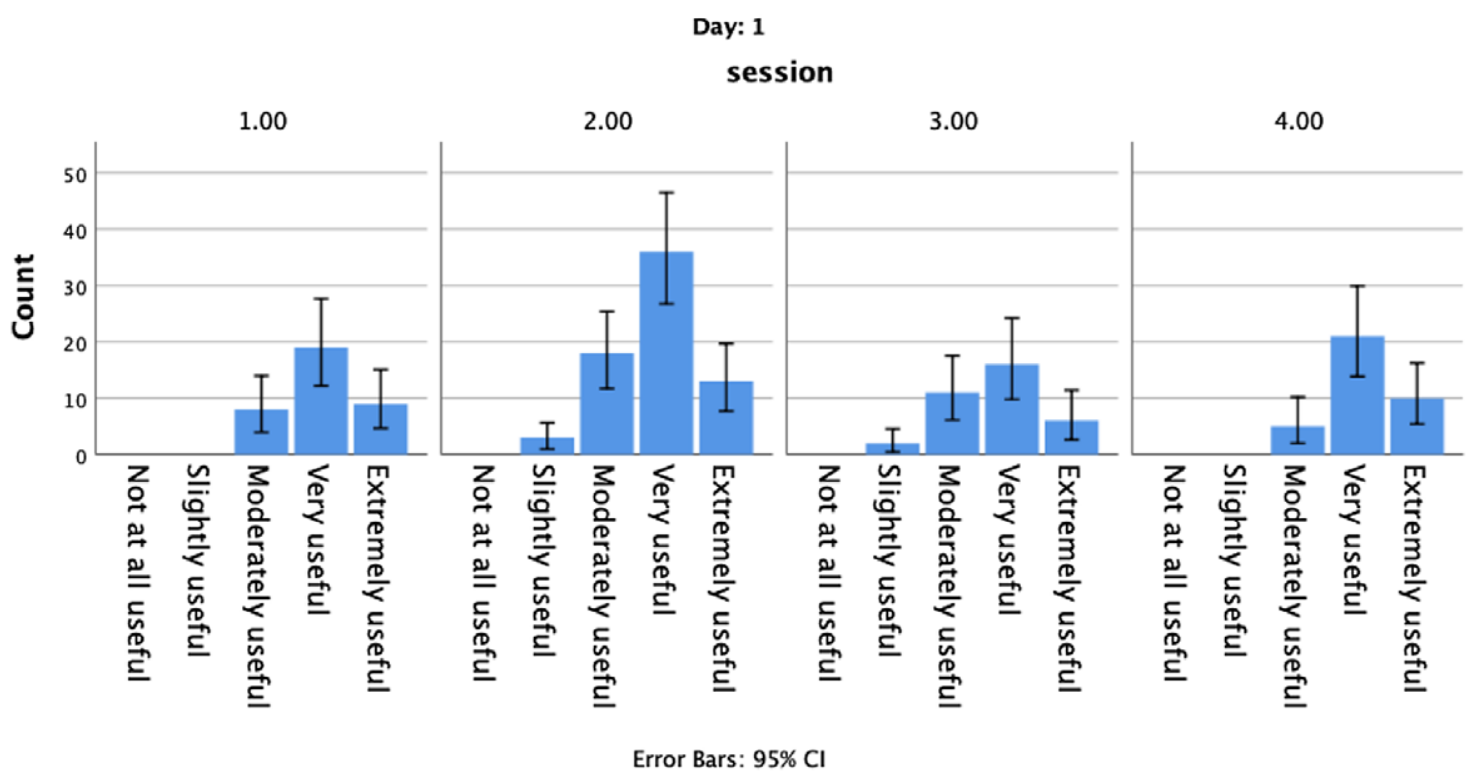

Fig. 3. Participants' ratings on Day 1 sessions: perceived usefulness.

Session 1: An overview of the empirical evidence supporting best practices for team science

Session 2: Self-assessment quiz and the establishment of your team's rules

Session 3: Tech platforms for project management and knowledge management options

Session 4: Psychological safety exercise: What you should know about me/my discipline

with a very small number of participants responding with low ratings on a couple of sessions for both days. However, responses to individual sessions varied significantly. Results from a repeatedmeasure ANOVA indicate that there were significant differences in usefulness/applicability $(F(3,99)=4.11, p=.009)$ across the four workshop sessions given on Day 1 as well as across the five sessions given on Day $2(F(4,148)=6.75, p<.05)$. As shown in Figures $1-6$, participants perceived sessions that provided technological platforms for project management and knowledge management options to be the least useful/applicable for their work, while the keynote address delivered by a prominent scholar was perceived to be the most effective and useful/applicable. 


\section{Influence on Team's work}

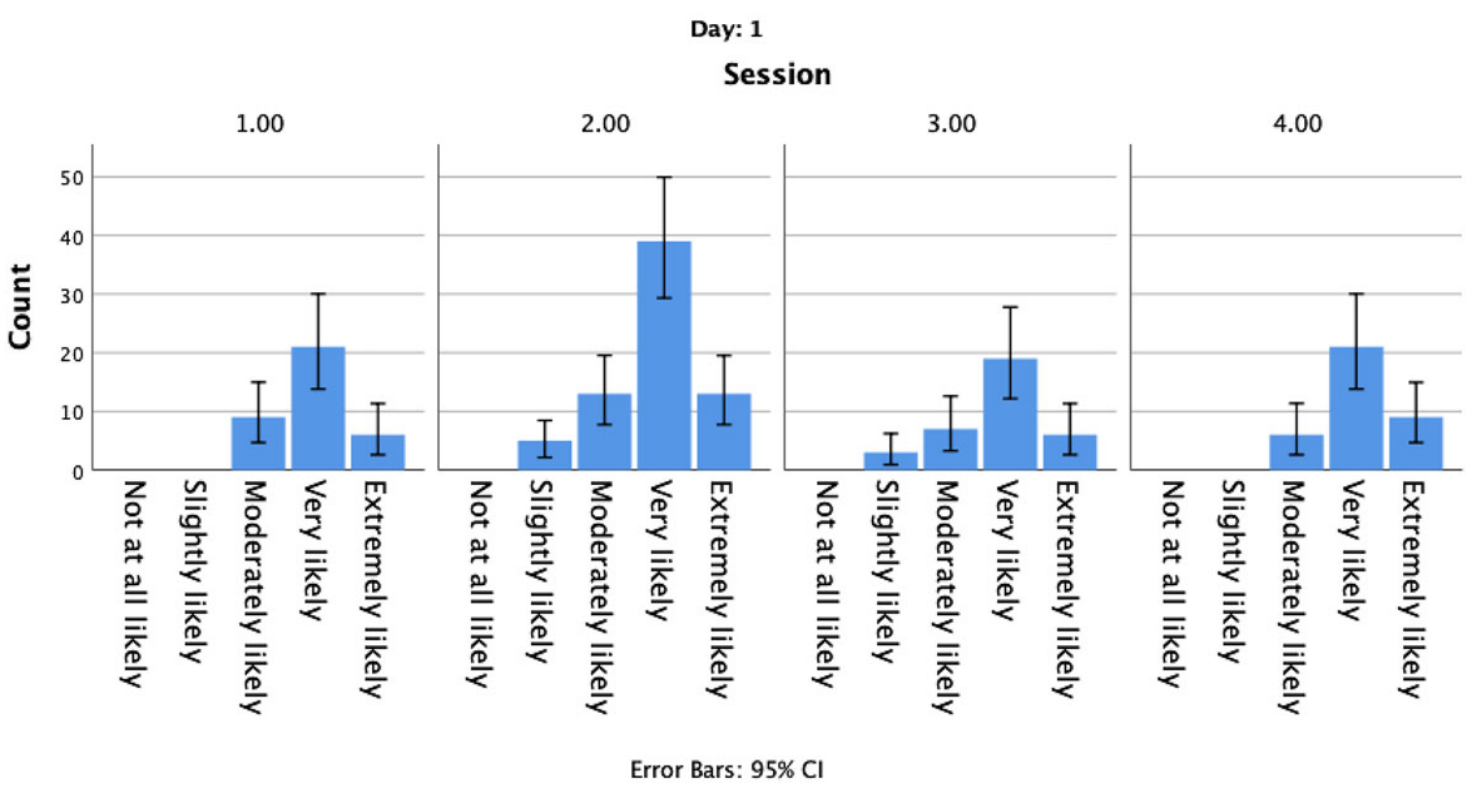

Fig. 4. Participants' ratings on Day 1 sessions: influence on teams' work.

Session 1: An overview of the empirical evidence supporting best practices for team science

Session 2: Self-assessment quiz and the establishment of your team's rules

Session 3: Tech platforms for project management and knowledge management options

Session 4: Psychological safety exercise: What you should know about me/my discipline

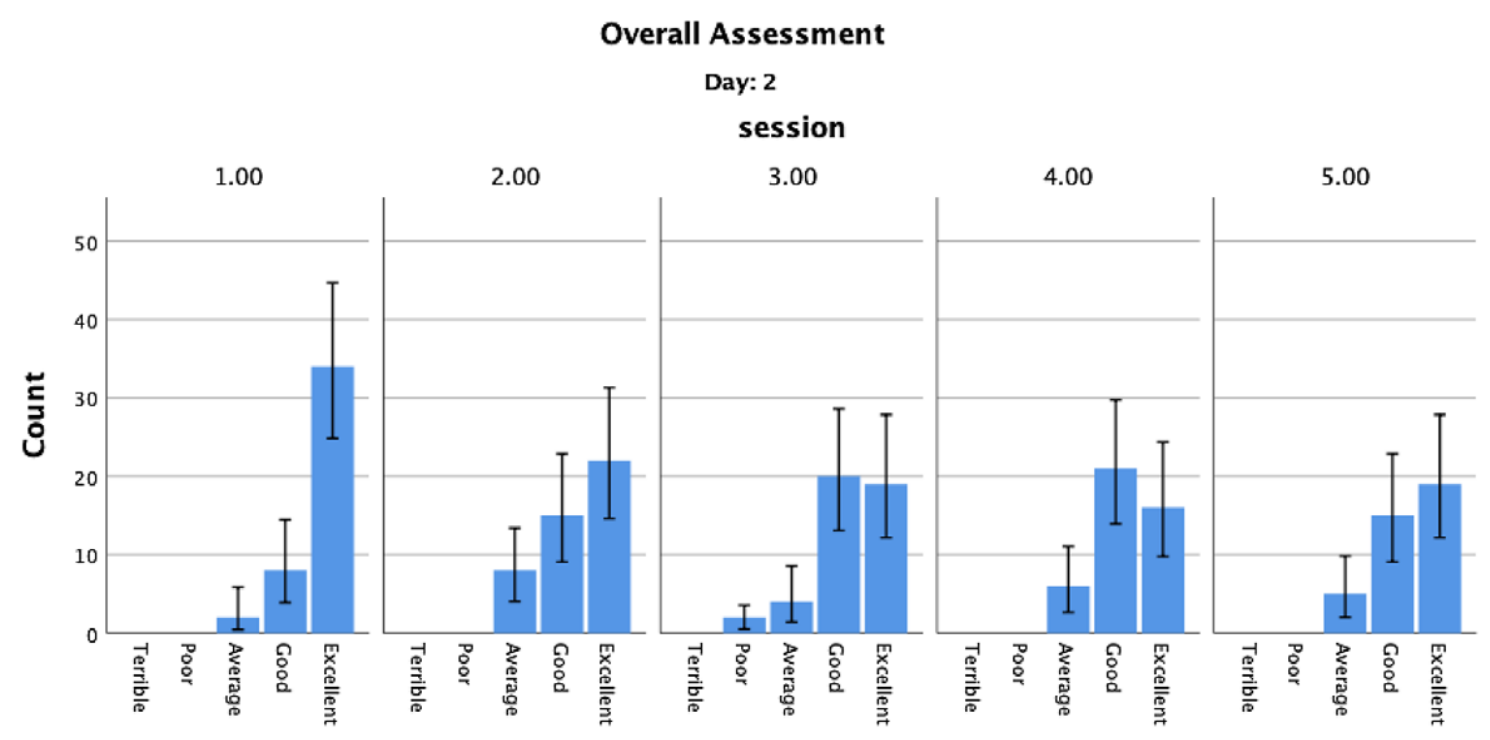

Error Bars: $95 \% \mathrm{Cl}$

Fig. 5. Participants' ratings on Day 2 sessions: overall assessments.

Session 1: Keynote address by external team science expert

Session 2: The importance of a team charter; creating your team's charter

Session 3: Communication behaviors that predict interdisciplinary team success; role play

Session 4: U-LINK team's calendar of activities; discussing your next steps

Session 5: Presentation of U-LINK Resources

\section{Impact of Team Development Intervention on Outcomes}

Individual-level outcome measures

No significant difference was found at T1 between those who attended the workshop and those who did not, indicating that any significant differences at posttest were a function of participation in the team science workshop. Individuals who participated in at least one workshop session $(M=4.63, S D=.47$, $n=28)$ scored higher at posttest on readiness to collaborate than those who did not $(M=4.06, S D=.65, n=11),(t(37)=3.04$, $p=.004$ ), supporting H1. Cohen's $d$ of 1.08 (95\% CI: 0.36 to 1.82) suggests a substantial difference between the two groups in 
Pereceived Usefulness

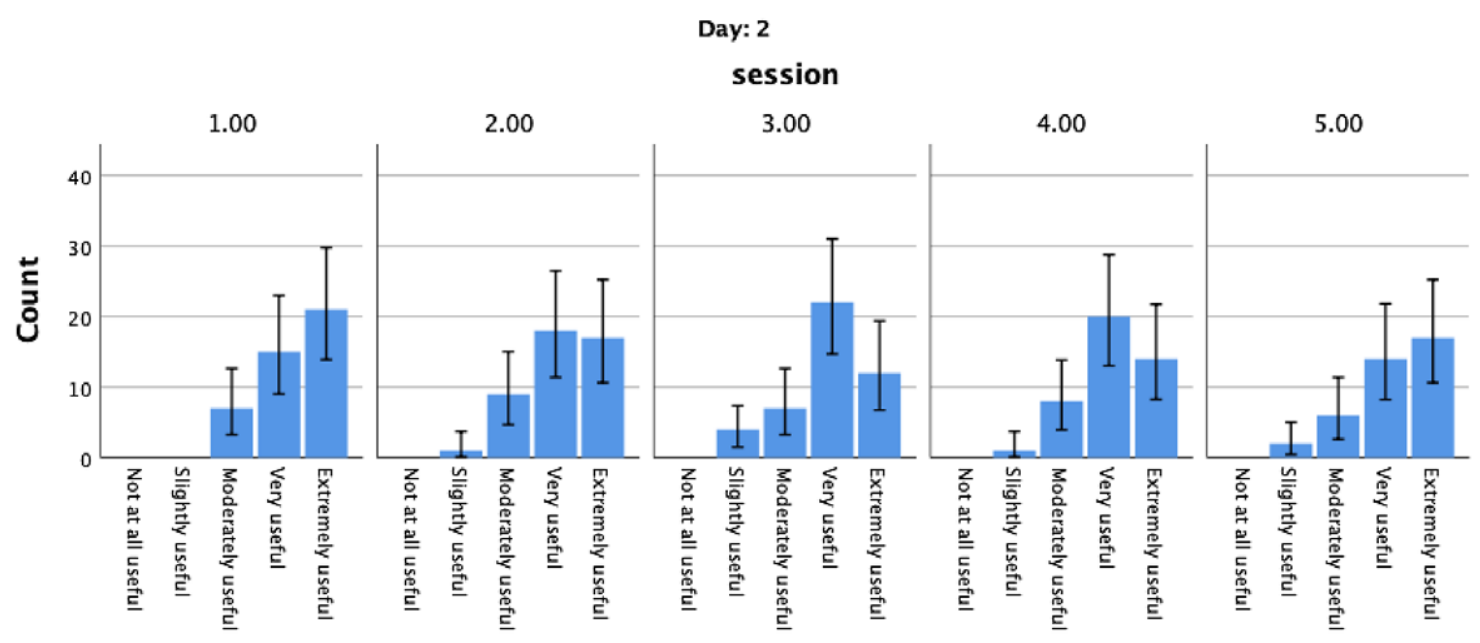

Error Bars: $95 \% \mathrm{Cl}$

Fig. 6. Participants' ratings on Day 2 sessions: Perceived usefulness. Session 1: Keynote address by external team science expert

Session 2: The importance of a team charter; creating your team's charter

Session 3: Communication behaviors that predict interdisciplinary team success; role play

Session 4: U-LINK team's calendar of activities; discussing your next steps

Session 5: Presentation of U-LINK Resources

Influence on Team's work

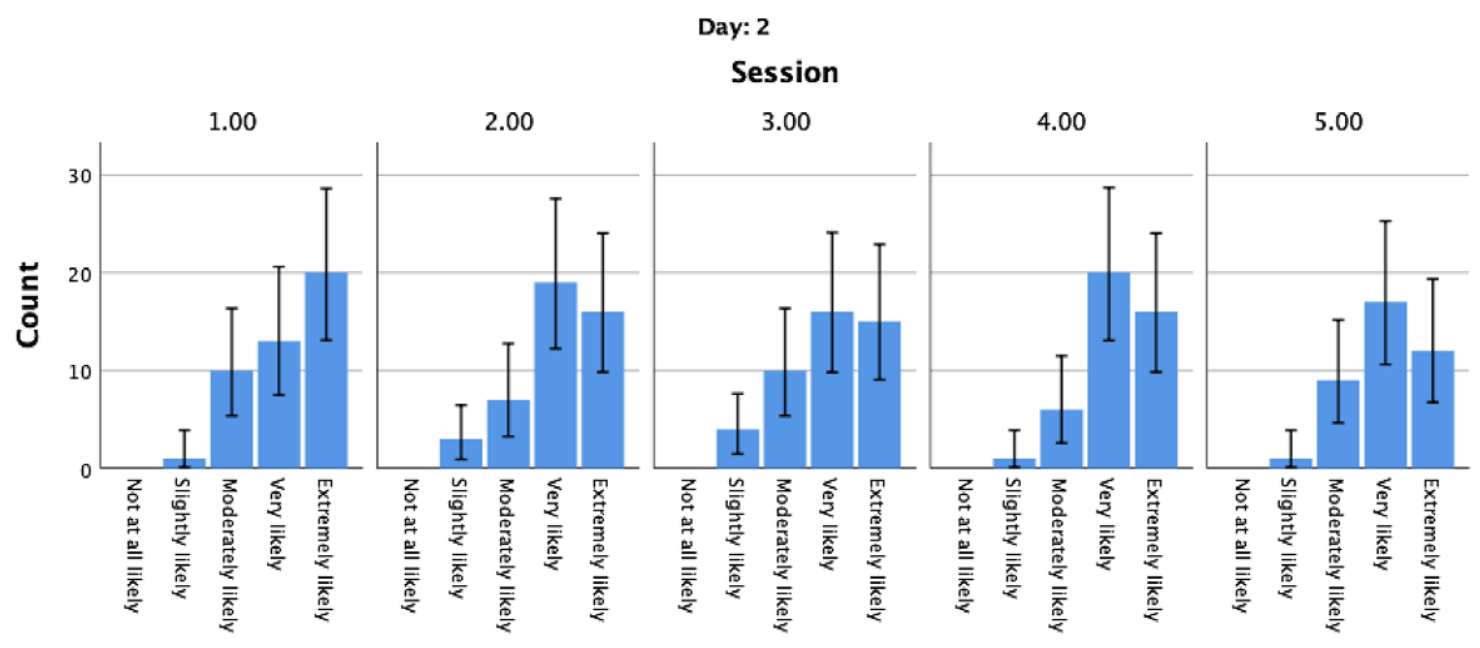

Error Bars: $95 \% \mathrm{Cl}$

Fig. 7. Participants' ratings on Day 2 sessions: influence on teams' work.

Session 1: Keynote address by external team science expert

Session 2: The importance of a team charter; creating your team's charter

Session 3: Communication behaviors that predict interdisciplinary team success; role play

Session 4: U-LINK team's calendar of activities; discussing your next steps

Session 5: Presentation of U-LINK Resources

individuals' perceived readiness to collaborate. This indicates that, on average, $86 \%$ of individuals who attended a workshop session had a higher mean on readiness to collaborate than those who did not. Figure 8 provides a visual representation of these results.

In addition, individuals who participated in at least one workshop session scored significantly higher on behavioral trust $(M=4.22, S D=.50, n=30)$ than those who did not $(M=3.77$, $S D=.68, n=11)$. Cohen's $d$ of 0.82 (95\% CI: 0.10 to 1.53 ) indicates a large difference between the two groups in an individual's behavioral trust level, suggesting that on average, $81 \%$ of individuals who attended a workshop session had a higher mean on behavioral trust level than those who did not. This difference was significant, $(t(39)=2.33, p=.03)$, which supports H5. Table 4 presents the results of individual-level hypotheses.

Results from independent samples $t$-tests did not find differences between individuals who participated in at least one 


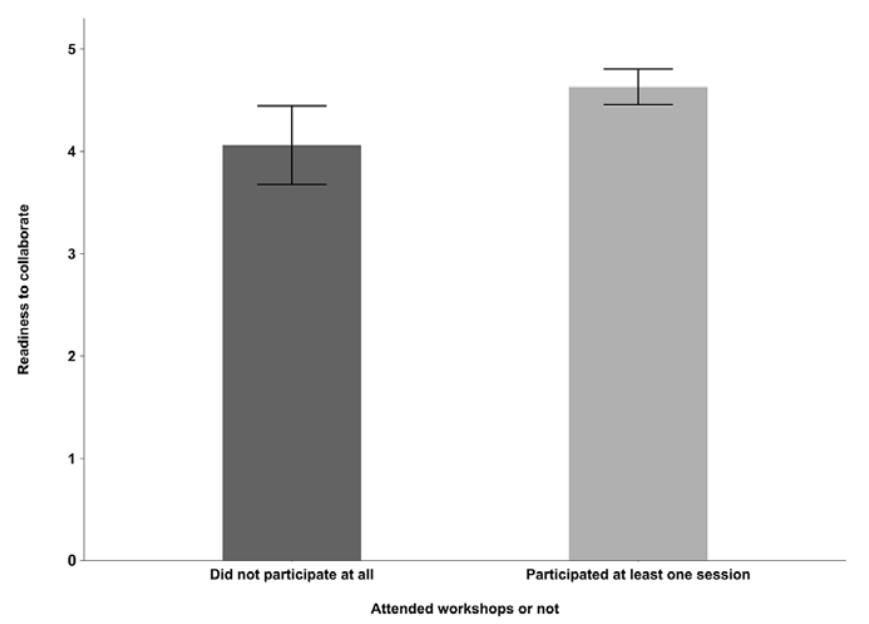

Fig. 8. Impact of team development intervention on readiness to collaborate.

team science workshop and those who did not on the other three distal outcome measures, including goal clarity, process clarity, and role ambiguity, which fails to support $\mathrm{H} 2, \mathrm{H} 3$, or $\mathrm{H} 4$. Results from the Mann-Whitney $U$ test suggest that teams were not different on team satisfaction as a result of workshop participation. Cohen's $d$ effects calculated from the Mann-Whitney $U$ statistics were small (0.04), likely because the study was underpowered. This means that H6 was not supported.

\section{Discussion}

In this study, we evaluated the impact of a team development workshop for novel, intact interdisciplinary teams on key outcomes. The U-LINK workshop included didactic lectures on empirically based best practices for collaborative teams, as well as skills-based modules on communication skills and creating psychological safety. Participants had the opportunity to enact their team science knowledge and skills during sessions on creating team rules, establishing a team charter, and planning a calendar of activities. These topics were selected based on the empirical literature on the science of team science indicating that the topics (1) represent knowledge, skills, and behaviors supporting collaboration that can be improved, and (2) are associated with team success.

Our evaluation drew upon both workshop evaluation forms and a pretest (T1)/posttest (T2) survey of participants on constructs related to team science. The results of the post-workshop evaluation indicate that nearly all of the workshop sessions were favorably evaluated. In particular, participants were enthusiastic about the keynote speaker's presentation that focused on empirical research on effective teams; the remaining sessions scored between 4.2 and 4.4 on a 5 -point scale, with just one exception. While liking and valuing material is no guarantee of positive outcomes in terms of individual attitudes and behaviors, the positive evaluations of these sessions indicate that participants value the material and find it useful.

Analyses of the survey results indicate that development interventions for interdisciplinary teams can improve some of the outcomes that are predictive of team success. Specifically, our data indicate that the team science workshop resulted in meaningful improvements in readiness to collaborate and team trust. The importance of this finding cannot be overstated; the influential work of Bennett and Gadlin [9] on predictors of the success of interdisciplinary teams emphasizes that of the key elements that are critical for team success, the "most important of these is trust" (p. 768) because all team interactions and communication behaviors suffer without it. However, we were unable to demonstrate improvements in other variables, including goal clarity, process clarity, and role ambiguity. Nonetheless, we believe that ongoing interactions within teams during the course of regular meetings may improve these outcomes over time; we are hopeful that these outcomes will have been enhanced because of participants' engagement in workshop activities. It should be noted, however, that some measures suffered from low reliability and require additional instrument development efforts from researchers.

Questions about the format, content, and the timing of team development programs remain. For example, our program was mandatory for all awardees and was scheduled within a month of the start date of the grant award. As a matter of design, this was intended to ensure that team members had an understanding of collaborative best practices before meaningful work began, rather than as a way to remedy entrenched problems with collaboration. Additionally, the program was offered to intact teams to maximize the potential for immediate real-world skill transference as well as to create a shared experience that could serve to foster team bonds $[48,49]$. There are almost infinite permutations of content, even when focused on key competencies identified in the empirical literature on best practices in supporting team science. Other programs may be intended to provide skills for individual researchers to enhance their ability to join interdisciplinary teams or to improve their performance (or comfort with interdisciplinary collaborations).

The most effective timing for team development programs is another issue worth consideration. Many argue that interventions that support more effective interdisciplinary collaborations should be offered in graduate school or even during undergraduate education $[10,26,50]$. While some researchers attend to the issue of whether it is preferable to intervene with intact teams versus individuals $[48,49]$, there has been little attention to the "perfect time" to offer interventions, likely because documenting differences in outcomes would require a large number of teams operating under similar conditions, all receiving the same interventions. Because the U-LINK program is designed for shared leadership rather than a traditional top-down "PI model" of responsibility and delegation, it was important that teams attended the workshop at the very beginning of their work, thus precluding options for providing initial workshops at other points in time. However, it should be noted that the U-LINK program provided at least three additional professional development workshops, lectures, and mixers during each academic year.

Additionally, questions remain about the intensity of the interventions needed to improve team outcomes. The duration of team development programs varies widely, from regular 1-hour seminars spaced every month or so $[10,23]$ to full-day short courses 2-3 times per year [51]. Our program consisted of two consecutive half-days at the beginning of teams' funding period. This is another design issue that warrants consideration by future program organizers, but there are scant data to indicate that there is a monotonic relationship between the number of hours of team development and improved team outcomes. However, a general consensus in the literature indicates that it is important to improve specific knowledge, skills, and attitudes, which would be difficult to accomplish in less than a full day. 
Table 4. Results of tests of individual-level hypotheses

\begin{tabular}{|c|c|c|c|c|}
\hline Hypothesis & $\begin{array}{l}n \text { of Group } 1 \\
\text { (attendees) }\end{array}$ & $\begin{array}{l}n \text { of Group } 2 \\
\text { (nonattendees) }\end{array}$ & $\begin{array}{l}\text { Independent } \\
t \text {-test statistic }\end{array}$ & $p$ value \\
\hline $\begin{array}{l}\text { H1: Individuals who attended a team workshop will score higher on readiness to } \\
\text { collaborate than those who did not attend }\end{array}$ & 28 & 11 & $t(37)=3.04$ & .004 \\
\hline $\begin{array}{l}\text { H2: Individuals who attend a team development workshop will score higher on goal } \\
\text { clarity than individuals who did not attend the workshop }\end{array}$ & 30 & 10 & $t(17.8)=.55$ & .59 \\
\hline $\begin{array}{l}\text { H3: Individuals who attend a team development workshop will score higher on } \\
\text { process clarity than individuals who did not attend the workshop }\end{array}$ & 30 & 9 & $t(15.5)=1.22$ & .23 \\
\hline $\begin{array}{l}\text { H4: Individuals who attend a team development workshop will exhibit less role } \\
\text { ambiguity than individuals who did not attend the workshop }\end{array}$ & 30 & 10 & $t(19.3)=.13$ & .90 \\
\hline $\begin{array}{l}\text { H5: Individuals who attend a team development workshop will score higher on } \\
\text { behavioral trust than individuals who did not attend the workshop }\end{array}$ & 30 & 11 & $t(39)=2.33$ & .03 \\
\hline
\end{tabular}

While the content of the U-LINK team science workshop was grounded in the recommendations that have emerged from the empirical literature on the science of team science, there is not enough of a body of evidence to link specific content to specific outcomes. Based on our experience and prior findings reported in the literature on the science of team science $[15,28,36,52]$ we recommend that team development workshops include the following components:

- One-day program to maximize participation

- Combination of didactic lectures presenting the evidence for best practices, hands-on skills development, and role plays to build communication skills and conflict management skills

- In-person participation of intact teams who experience the program together

- Inclusion of informal components where team members can enjoy each other's company: shared meals, team-building exercises, and a post-workshop happy hour can be helpful

Additionally, we would recommend that future programs focus more heavily on the in-person development of a team charter than our own program did. A separate half-day retreat following a team science workshop might be in order. Experienced team moderators may help to ensure that all voices and concerns are heard, particularly from those with less seniority, experience, and power. Teams that are required to complete a team charter near the beginning of their project work would likely report greater goal and process clarity and less role ambiguity than teams that do not create a charter.

There are other emerging strategies for supporting the development and function of interdisciplinary teams, including structural interventions. In particular, creating coordination centers can help scientific teams take innovative discoveries through to a translational stage $[53,54]$. This type of structural intervention provides recognition [54].

There are, of course, limitations to this study. While we had hoped for a higher response rate among our attendees, our study ultimately had unavoidable issues linked to the relatively small number of teams which received grant funding through our internal program. Additionally, of course, most of our hypotheses require analyses that acknowledge that our data are nested within teams, further compromising our statistical power. It is our hope, however, that the data presented here can contribute to further meta-analyses and thoughtful discussions about the ideal design for team development programs.

\section{Conclusion}

This study was designed to assess the efficacy of an interdisciplinary team development program that was part of a larger effort to support the success of novel teams (i.e., those with no previous experience working together) who received pilot funding to work toward developing viable solutions for grand challenges to society. It was our hope to contribute to the body of evidence that institutions can increase the chances that an interdisciplinary team will succeed by providing a brief team development program. Indeed, data collected before, during, and after the program indicate that the program was well-received and produced meaningful improvements in readiness to collaborate and behavioral trust. While we were not able to demonstrate increases in long-term outcomes, our ability to thoroughly assess the impacts of this program was limited by a small sample size of teams and the nesting of individual survey responses within teams, which compromises statistical power. Overall, however, the pattern of findings is consistent with the larger body of research that indicates that a team development workshop constitutes a worthwhile investment for universities and institutes. The incorporation of innovative mechanisms to support team development (like simulations that would prepare teams for common obstacles to effective collaboration) and cutting-edge measurement techniques, like electronic badges, that can provide evidence of the impact of development interventions on actual real-world behavior [55] would advance this area of research further. It is our hope that the description of this program and its evaluation provide a blueprint that will prove useful for others as they design interdisciplinary research programs designed to address grand challenges to society.

Supplementary Material. To view supplementary material for this article, please visit https://doi.org/10.1017/cts.2021.831.

Acknowledgements. The authors are grateful to all of the U-LINK awardees who responded to the surveys. Without their participation, this evaluation would not have been possible.

Disclosures. The authors have no conflicts of interest to declare.

\section{References}

1. Hughes AM, Zajac S, Woods AL, Salas E. The role of work environment in training sustainment: A meta analysis. Human Factors 2020; 62: 166-183.

2. Harris MS, Holley K. Constructing the interdisciplinary ivory tower: The planning of interdisciplinary spaces on university campuses. Planning for Higher Education 2008; 36(3): 34-43. 
3. Fiore SM, Gabelica C, Wiltshire TJ, Stokols D. Training to Be a (Team) Scientist. 2019 In: Hall KL, Vogel AL, Croyle RT, eds. Strategies for Team Science Success: Handbook of Evidence-Based Principles for CrossDisciplinary Science and Practical Lessons Learned from Health Researchers. Cham: Springer International Publishing, 2019, pp. 421-444.

4. Lotrecchiano GR, Mallinson TR, Leblanc-Beaudoin T, Schwartz LS, Falk-Krzesinski HJ. Individual motivation and threat indicators of collaboration readiness in scientific knowledge producing teams: a scoping review and domain analysis. Heliyon 2016; 2(5): e00105. https://doi.org/ 10.1016/j.heliyon.2016.e00105.

5. Lacerenza CN, Salas E. Improving collaboration: Guidelines for team training. Journal of Translational Medicine \& Epidemiology 2014; 2: 2-5.

6. Falk-Krzesinski HJ, Contractor N, Fiore SM, et al. Mapping a research agenda for the science of team science. Research Evaluation 2011; 20(2): 145-158. doi: 10.3152/095820211X12941371876580.

7. Edmondson AC, Harvey JF. Cross-boundary teaming for innovation: Integrating research on teams and knowledge in organizations. Human Resource Management Review 2018; 28(4): 347-360.

8. Hinrichs MM, Seager TP, Tracy SJ, Hannah MA. Innovation in the Knowledge Age: implications for collaborative science. Environment Systems and Decisions 2016; 2016(37): 1-12.

9. Bennett LM, Gadlin H. Collaboration and team science: from theory to practice. Journal of Investigative Medicine 2012; 60(5): 768-75.

10. Cooke NJ, Hilton ML. Enhancing the Effectiveness of Team Science. Washington, DC: National Academies Press, 2015.

11. Baldwin R, Chang D. Collaborating to learn, learning to collaborate. Peer Review 2007; 9: 26-30.

12. Wuchty S, Jones BF, Uzzi B. The increasing dominance of teams in production of knowledge. Science 2007; 316(5827): 1036-1039.

13. Jeong $\mathbf{S}$, Choi JY. Collaborative research for academic knowledge creation: How team characteristics, motivation, and processes influence research impact. Science and Public Policy 2015; 42(4): 460-473.

14. Wildman JL, Bedwell WL. Practicing what we preach: Teaching teams using validated team science. Small Group Res 2013; 44(4): 381-394.

15. Klein C, DiazGranados D, Salas E et al. Does team building work? Small Group Research 2009; 40(2): 181-222.

16. Cheruvelil KS, Soranno PA, Weathers KC, et al. Creating and maintaining high-performing collaborative research teams: the importance of diversity and interpersonal skills. Frontiers in Ecology and the Environment 2014; 12: 31-38.

17. Bishop PR, Huck SW, Ownley BH, Richards JK, Skolits G. Impacts of an Interdisciplinary Research Center on Participant Publication and Collaboration Patterns. Research Evaluation 2014; 23(4): 327-340.

18. Hargadon AB, Bechky BA. When collections of creatives become creative collectives: A field study of problem solving at work. Organization Science 2006; 17(4): 484-500.

19. Lotrecchiano GR. A dynamical approach toward understanding mechanisms of team science: Change, kinship, tension, and heritage in a transdisciplinary team. Clinical and Translational Science 2013; 6(4): 267-278.

20. Lotrecchiano GR, et al. Individual and Team Competencies in Translational Teams. Journal of Clinical and Translational Science 2020; e.: $1-20$.

21. Olivero O. Interdisciplinary Mentoring in Science: Strategies for Success. Cambridge, MA: Academic Press; 2013.

22. Salazar MR, Lant TK. Facilitating innovation in interdisciplinary teams: The role of leaders and integrative communication. Informing Science 2018; 1: 21.

23. Begg MD, Crumley G, Fair AM, et al. Approaches to preparing young scholars for careers in interdisciplinary team science. Journal of Investigative Medicine 2014; 62(1): 14-25. doi: 10.2310/JIM.0000000 000000021.

24. Dolor RJ, Greene SM, Thompson E, et al. Partnership-driven resources to improve and enhance research (PRIMER): a survey of community-engaged researchers and creation of an online toolkit. Clinical and Translational Science 2011; 4(4): 259-265.

25. DuBois JM, Schilling DA, Heitman E, et al. Instruction in the responsible conduct of research: An inventory of programs and materials within CTSAs. Clinical and Translational Science 2010; 3(3): 109-111.
26. Nash JM, Collins BN, Loughlin SE, et al. Training the transdisciplinary scientist: A general framework applied to tobacco use behavior. Nicotine \& Tobacco Research 2003; 5(Suppl_1): S41-53.

27. Wooten KC, Rose RM, Ostir GV, et al. Assessing and evaluating multidisciplinary translational teams: a mixed methods approach. Evaluation of the Health Professions 2014; 37(1): 33-49. doi: 10.1177/ 0163278713504433.

28. Wooten KC, Calhoun WJ, Bhavnani S, et al. Evolution of multidisciplinary translational teams (MTTs): insights for accelerating translational innovations. Clinical and Translational Science 2015; 8(5): 542-552.

29. Marlow SL, Lacerenza CN, Paoletti J, Burke CS, Salas E. Does team communication represent a one-size-fits-all approach? A meta-analysis of team communication and performance. Organizational Behavior and Human Decision Processes 2018; 144: 145-170.

30. Antes AL, Mart A, DuBois JM. Are Leadership and Management Essential for Good Research? An Interview Study of Genetic Researchers. Journal of Empirical Research on Human Research Ethics 2016; 11(5): 408-423. doi: $10.1177 / 1556264616668775$.

31. Khuri S. Multifaceted discipline-agnostic approach to training transdisciplinary teams in communication In: Lotrecchiano GR, Misra S. eds. Communication in Transdisciplinary Teams. Santa Rosa, CA: Informing Science Press, 2010, pp. 293-308.

32. Stevens MJ, Campion MA. The knowledge, skill, and ability requirements for teamwork: Implications for human resource management. Journal of Management 1994; 20(2): 503-530.

33. Verderame MF, Freedman VH, Kozlowski LM, et al. Point of View: Competency-based assessment for the training of $\mathrm{PhD}$ students and early-career scientists. Elife 2018; 7: e34801.

34. Belkhouja M, Yoon HD. How does openness influence the impact of a scholar's research? An analysis of business scholars' citations over their careers. Research Policy 2018; 47(10): 2037-47.

35. Spring B, Klyachko EA, Rak PW, et al. Online, cross-disciplinary team science training for health and medical professionals: Evaluation of COALESCE (teamscience. net). Journal of Clinical and Translational Science 2019; 3(2-3): 82-9.

36. Vogel AL, Feng A, Oh A, et al. Influence of a National Cancer Institute transdisciplinary research and training initiative on trainees' transdisciplinary research competencies and scholarly productivity. Translational Behavioral Medicine 2012; 2(4): 459-468. doi: 10.1007/s13142-0120173-0.

37. Keck AS, Sloane S, Liechty JM, et al. Productivity, impact, and collaboration differences between transdisciplinary and traditionally trained doctoral students: A comparison of publication patterns. PLOS ONE 2017; 12(12): e0189391. https://doi.org/10.1371/journal.pone.0189391.

38. Delise LA, Allen Gorman C, Brooks AM, et al. The effects of team training on team outcomes: A meta-analysis. Performance Improvement Quarterly 2010; 22(4): 53-80.

39. Miller K, Ben-Knaan K, Clark Hughes A, et al. Works in Progress Webinar: Librarians on Interdisciplinary Research Teams-a Case Study from the University of Miami [Video]. OCLC. 2020. (https://www.oclc. org/research/events/2020/091020-librarians-interdisciplinary-researchteams-case-study.html)

40. Lacerenza CN, Marlow SL, Tannenbaum SI, Salas E. Team development interventions: Evidence-based approaches for improving teamwork. American Psychologist 2018; 73(4): 517.

41. Hall KL, Stokols D, Moser RP, et al. The collaboration readiness of transdisciplinary research teams and centers findings from the National Cancer Institute's TREC Year-One evaluation study. American Journal of Preventive Medicine 2008; 35(2 Suppl): S161-S172. doi: 10.1016/j. amepre.2008.03.035.

42. Gillespie N. Measuring trust in relationships: The behavioral trust inventory. Acad Mgmt Conf, August 2003, Seattle, WA 2003.

43. Sawyer JE. Goal and process clarity: Specification of multiple constructs of role ambiguity and a structural equation model of their antecedents and consequences. Journal of Applied Psychology 1992; 77(2): 130.

44. Peterson MF, Smith PB, Akande A, et al. Role conflict, ambiguity, and overload: A 21-nation study. Academy of Management Journal 1995; 38(2): 429-452. 
45. Hackman JR, Oldham GR. The Job Diagnostic Survey: An instrument for the diagnosis of jobs and the evaluation of job redesign projects. 1974; (No. ED099580). Office of Naval Research. (https://eric.ed.gov/? $\mathrm{id}=\mathrm{ED} 099580)$

46. Gamst G, Meyers LS, Guarino AJ. Analysis of variance designs: A conceptual and computational approach with SPSS and SAS. Cambridge University Press; 2008.

47. Kerby DS. The simple difference formula: An approach to teaching nonparametric correlation. Comprehensive Psychiatry 2014; 3: 11-IT.

48. Fernandez R, Shah S, Rosenman ED, et al. Developing Team Cognition: A Role for Simulation. Simulation in Healthcare 2017; 12(2): 96-103. doi: 10. 1097/SIH.0000000000000200.

49. Liang DW, Moreland R, Argote L. Group versus individual training and group performance: The mediating role of transactive memory. Personality and Social Psychology Bulletin 1995; 21(4): 384-393.
50. Klein WM. Cross-disciplinary team science with trainees: From undergraduate to postdoc. Strategies for Team Science Success. Cham: Springer, 2019, pp. 469-474.

51. Gibert A, Tozer WC, Westoby M. Teamwork, soft skills, and research training. Trends in Ecology \& Evolution 2017; 32(2): 81-84.

52. Read EK, O'Rourke M, Hong GS, et al. Building the team for team science. Ecosphere 2016; 7(3): e01291.

53. Gehlert S, Hall K, Vogel A, et al. Advancing Transdisciplinary Research: The Transdisciplinary Research on Energetics and Cancer Initiative. Journal of Translational Medicine \& Epidemiology 2014; 2(2): 1032.

54. Rolland B, Lee CP, Potter JD. Greater than the sum of its parts: A qualitative study of the role of the coordinating center in facilitating coordinated collaborative science. Journal of Public Administration Research and Theory 2017; 48(1): 65-85.

55. Pentland AS. The new science of building great teams. Harvard Business Review 2012; 90: 61-70. 